This is the pre-peer reviewed version of the following article:

Rodriguez-Moreno, S., Vázquez, J.J., Roca, P., \& Panadero, S. (2020). Differences in stressful life events between men and women experiencing homelessness. Journal of Community Psychology, 1-15,

which has been published in final form at:

https://doi.org/10.1002/jcop.22465

This article may be used for non-commercial purposes in accordance with Wiley Terms and Conditions for Use of Self-Archived Versions. 
Author's Pre-print of the article:

Rodriguez-Moreno, S., Vázquez, J.J., Roca, P., \& Panadero, S. (2020). Differences in stressful life events between men and women experiencing homelessness. Journal of Community Psychology, 1-15. DOI: doi.org/10.1002/jcop.22465

Copyright: (C) Wiley Periodicals, Inc.

\section{DIFFERENCES IN STRESSFUL LIFE EVENTS BETWEEN MEN AND WOMEN EXPERIENCING HOMELESSNESS}

Sara Rodriguez-Moreno ${ }^{1}$, José Juan Vázquez ${ }^{2}$, Pablo Roca ${ }^{1}$ and Sonia Panadero ${ }^{1}$

1. Clinical Psychology Department, School of Psychology, Complutense University of Madrid, 28223, Madrid, Spain.

2. Social Psychology Department. Alcala University, 28801, Alcala de Henares. Madrid, Spain.

Corresponding author: Sara Rodriguez-Moreno, Clinical Psychology Department, Psychology School, Complutense University of Madrid, 28223, Madrid, Spain. Email: sarairod@ucm.es

Acknowledgements: Sara Rodriguez-Moreno is a $\mathrm{PhD}$ candidate at Complutense University of Madrid and this work will be part of her PhD work on mental health and psychological treatments in homeless women. The authors want to thank all women experiencing homelessness for their generosity to participate in the study.

Funding statement: This research was supported by the "Agencia Estatal de Investigación" of the "Ministerio de Economía, Industria y Competitividad" of Spain (Ref. FEM2016-75317-R; Ref. PSI2009-08472; Ref: FEM2012-35053) and Complutense-Santander Back grant (ref: CT17/17-CT18/17) to SRM.

Conflicts of interest: None of the authors have any conflict of interest. 


\begin{abstract}
People experiencing homelessness are particularly vulnerable to experience Stressful Life Events (SLEs) at some point in their lives, and these SLEs are crucial for understanding the etiology and maintenance of homelessness. This study analyses the differences between men and women experiencing homelessness in the suffering of SLEs throughout their lives (childhood, adolescence, and adulthood). The sample consisted of a group of 293 people living homeless in Madrid (Spain): 156 men and 137 women. The results suggest that the number and type of SLEs experienced by men and women are different. In general, women experiencing homelessness suffer more SLEs than men at all periods of their lives. The differences in the level of sexual violence in childhood, sexual abuse in adulthood, and abuse by a spouse or partner are particularly striking. However, men experiencing homelessness score significantly higher than women for alcohol abuse, police complaints, arrest, and imprisonment throughout their lives. These findings have significant implications for the design of interventions and social policies sensitive to the specific needs of men and women who are homeless.
\end{abstract}

Keywords: people experiencing homelessness, homelessness, stressful life events, gender, women experiencing homelessness. 


\section{Introduction}

According to the European Commission (2009), people experiencing homelessness may be considered one of the most socially excluded groups in Western societies, as it is a major violation of human rights. Unfortunately, homelessness affects millions of people worldwide each year: around four million people are in a homeless situation in Europe and around three million in the U.S. (Fazel et al., 2014). Furthermore, individuals experiencing homelessness not only live in extreme poverty, but also experience high levels of family and social disengagement, have significant physical and mental health problems, and great difficulties in achieving social and employment reintegration (Vázquez et al., 2018), among others.

Research has particularly highlighted how Stressful Life Events (henceforth SLEs) are a very important factor in people originating and sustaining of homeless (Jasinski et al., 2005; Muñoz et al., 2005; Padgett et al., 2012). SLEs are defined as experiences that play a key role in people's lives and which involve significant changes. Studies have shown that people living homeless experience an extraordinarily large number of SLEs in the course of their lives, largely before or during their transition to homelessness (Muñoz et al., 1999; Vázquez et al., 2019), and there is an inverse correlation between the number of events experienced and the age at which the individual becomes homeless (Brown et al., 2016; Koegel et al., 1995).

Particular attention has focused on SLEs occurring during the childhood of people experiencing homelessness. Studies conducted on both European and U.S.-based samples have shown that these individuals often present indicators of dysfunctional home backgrounds, with a history of physical and/or sexual abuse in childhood, parental substance abuse or mental illness, running away from home, and institutionalization (Herman et al., 1997; Padgett et al, 2012; Panadero et al., 2018; Wong \& Piliavi, 2001).

In the specific case of women experiencing homelessness, although they have become more visible in recent years, they have traditionally been invisible (Barrow, 2004). Moreover, the lack of evidence on individuals experiencing homelessness under a gender perspective aggravates this issue (Mayock \& Bertherton, 2016). However, some authors have argued that gender could determine experiences of exclusion, being a crucial factor to understand the paths toward a homeless situation, the experiences during homelessness and the opportunities to access housing resources (Bowpitt et al., 2011; Bretherton, 2017; Johnson et al., 2017; Montgomery et al., 2017). For instance, some studies have found that women are more likely to experience more episodes of homelessness -albeit shorter ones- (Johnson et al, 2017), they are less likely to be literally living on the street (Byrne et al., 2016; Johnson et al., 2017) and they have an increased risk of premature mortality (Montgomery et al., 2017).

Some of these events, such as physical and/or sexual abuse in childhood, appear to be particularly common among women who are homeless (Noell et al., 2001; Sundin \& Baguley, 2015; Vázquez \& Panadero, 2019; Zugazaga, 2004). Women experiencing homelessness have higher rates of physical and sexual abuse than women in the general population, being an important risk factors for the homelessness (Jasinski et al., 2005). In their systematic review and meta-analysis about childhood abuse among people experiencing homelessness, Sundin \& Baguley (2015) found a prevalence of sexual abuse in childhood of $32 \%$ for homeless women, and $10 \%$ for men. Unfortunately, this victimization also appears to continue in these women's adult lives. Several studies conducted on cross-national samples also highlight the high prevalence of physical and 
sexual violence among women living homeless throughout their lives (Jasinski et al., 2005; Vázquez \& Panadero, 2019; Wenzel et al., 2001), and specifically discuss gender violence among these women (Bassuk et al., 2006; Johnson et al., 2017). However, some authors with U.S.-based samples have found no differences compared to women in other situations of social exclusion, with the percentages of victimization due to gender violence being very high in both cases (Bassuk et al, 1997; Lehman et al., 2007). Knowledge of the different characteristics and needs of men and women could enable social services and policies sensitive to these differences to be designed (Tsai et al., 2014), and more effective responses to be provided to the different needs of homeless population.

Thus, the aim of this study was to examine the differences between men and women who were homeless in terms of the number and type of SLEs experienced during their lives (childhood, adolescence and adulthood). Three main hypotheses were set up: 1) women experiencing homelessness would suffer a greater number of SLEs than men experiencing homelessness; 2) women living homeless would experience different types of SLEs than their male counterparts; and 3) these gender differences would be found in the different lives periods (childhood, adolescence and adulthood).

\section{Method}

\section{Participants}

This study was carried out with a sample of 158 men experiencing homelessness and a sample of 138 women experiencing homelessness in the city of Madrid (Spain). However, three participants were excluded due to presenting missing values in the entire section referring to SLEs, which reduced the final sample in the study from 296 to 293 people living homeless. Inclusion criteria were being over 18 years, providing informed consent, and spending the night before the interview in a shelter or other facility for homeless people, on the street or in other places not initially designed for sleeping: abandoned buildings, basements, metro stations, and so forth (Panadero et al., 2018). Exclusion criteria were not being able to understand the interview questions in Spanish or English and serious cognitive impairments or alcohol/drug effects during the interview.

The number of individuals experiencing homelessness in Madrid (Spain) is well determined by the data at the Madrid City Council Count every two year (i.e., a central record of individuals who spent the night in shelters and other services for homeless, or people who spent the night on the street or in other transitory public places frequented by people experiencing homelessness, such as bus/train stations, parks, and street places). In this study, the sample size of homeless men $(n=156)$ was determined a priori, based on the number of individuals experiencing homelessness in Madrid (Panadero \& Vázquez, 2016). Men who were homeless were selected using a proportional stratified random sampling strategy in (1) all shelters and other accommodations for homeless (based on the capacity of each facility), and (2) on the streets based on the number of men who were homeless sleeping on the streets of Madrid (Vazquez et al., 2018). Given the relatively small number of women living homeless in Madrid (between the 15-20\% of the total people living homeless; Panadero \& Vázquez, 2016), the women experiencing homelessness were selected using a convenience sampling strategy $(n=137)$ in shelters and care facilities for homeless women, and on the street. 


\section{Materials}

A structured interview was used in order to guarantee the homogeneity of the data collected and to overcame potential problems arising from the participants' literacy levels. An adapted version of the List of stressful life events for groups in social exclusion (LSVE) (Panadero et al., 2018) was used. This instrument has been used with various groups in social exclusion in previous research (Guillén et al., 2015; Vázquez \& Panadero, 2019). The scale consists of a 45 SLEs with dichotomy answers (yes/no). The scale was designed to use each event separately or to aggregate the events into three main factors: "SLEs in childhood/adolescence", "SLEs throughout life" and "total SLEs score" (aggregating all the items). In the current study, the internal consistency was $\alpha=.79$ for "childhood/adolescence" factor, $\alpha=.70$ for "throughout life" factor, and $\alpha=.80$ for the total SLEs score.

\section{Procedure}

A specialized team of interviewers and coders was trained in the use of the structured interview, and in dealing with people in situations of social exclusion. After the interviewee had been selected, the interviewer checked their compliance with the inclusion and exclusion criteria. The objectives of the research and the anonymous and confidential treatment of the data obtained were briefly explained to the interviewee in order to finally request their informed consent for participation in the research. To ensure the confidentiality and anonymity of the responses, the interviews were conducted in a private environment: offices loaned by the shelters, places away from crowds, bedrooms, etc. Furthermore, the research was approved by a university ethics committee prior to participant recruitment.

\section{Statistical analysis}

Following the above hypotheses, the data analysis was divided into two steps: 1) Mann-Whitney $U$ non-parametric contrast was used to analyze the differences in the number of SLEs experienced by men and women experiencing homelessness. MannWhitney $U$ was carried out instead of Student $t$ test because normality, homoscedasticity and independence assumptions were not fulfilled for any of the three SLE scores (i.e. total SLEs in childhood, total SLEs throughout their life, and total SLEs); 2) Chi-square test $\left(\chi^{2}\right)$ was used to examine the different types of SLEs suffered by men and women experiencing homelessness, using 2 (men/women) x 2 (yes/no SLEs) contingency tables. The assumption of independence observations and the minimum number of cases per cell (i.e. less than $20 \%$ of the expected frequencies are less than 5) was confirmed prior to the analyses. For all the analyses: a) basic assumptions were tested; b) effect sizes were calculated: Cohen's $d$ for quantitative variables and the Phi $(\phi)$ and Odds Ratios (OR) for qualitative variables; and c) power analysis were carried out ( 1 - $\beta$ ). SPSS v.22 was used for all analyses.

A multiple imputation procedure was carried out for treating the missing values following the procedure suggested by Hair and colleagues (2014): 1) the type of missing data was explored, concluding that only item-level data were missing; 2) there were only $1.9 \%$ of total missing values; 3 ) Little MCAR test was carried out to diagnose the random pattern of missing data $\left(\chi^{2}(1563)=1812.64, p<.05\right)$ concluding that missing data were not completely random and should be imputed (Arias et al., 2015); 4) finally, sensitivity analysis was carried out comparing the results of completers to the imputed values to ensure that the imputation had not generated biased estimations. 


\section{Results}

The final sample consisted of 156 men (53.2\%) and 137 women (46.8\%), with an overall mean age of 46.35 years $(S D=11.93)$, who were mostly Spanish $(71.3 \%)$ and single $(57 \%)$. Within the men group, the mean age was 47.03 years $(S D=12.37), 73.5 \%$ were Spanish, and 55.1\% were single. Regarding the women group, the mean age was $45.58(S D=11.40), 68.7 \%$ were Spanish, and $59.1 \%$ were single. No significant differences between groups were found in age $(t(291)=1.04, p=.30)$, nationality $\left(\chi^{2}(1)=\right.$ $.82, p=.37)$ or marital status $\left(\chi^{2}(5)=6.27, p=.28\right)$.

\section{Differences in the number of stressful life events experienced by men and women living homeless}

Table 1 shows the means and standard deviations of the various SLEs total scores. In general, and regardless of gender, the people living homeless experienced a great deal of SLEs, in childhood/adolescence, throughout their lives and in total. However, when these means are analyzed according to gender, homeless women are found to experience more SLEs in all the categories.

Table 1: Means and standard deviations of the number of stressful life events

\begin{tabular}{cccc}
\hline & Gender & $\begin{array}{c}\text { Total mean } \\
(\mathrm{SD})\end{array}$ & $\begin{array}{c}\text { Mean per group } \\
\text { (SD) }\end{array}$ \\
\hline $\begin{array}{c}\text { SLEs in childhood } \\
\text { and adolescence }\end{array}$ & Men & \multirow{2}{*}{$4.62(3.07)$} & $3.72(3.05)$ \\
\hline $\begin{array}{c}\text { SLEs throughout } \\
\text { life }\end{array}$ & Men & \multirow{2}{*}{$9.44(3.81)$} & $\begin{array}{c}8.64(4.12) \\
10.38(4.12)\end{array}$ \\
\hline \multirow{2}{*}{ Total SLEs } & Women & & $12.33(5.15)$ \\
& Men & \multirow{2}{*}{$14.06(6.32)$} & $16.02(6.95)$ \\
\hline
\end{tabular}

The Mann-Whitney $U$ test showed statistically significant differences between men and women experiencing homelessness for the three SLE scores (see Table 2). The range of means shows that women experienced significantly more SLEs than men in childhood and adolescence, throughout their lives and in total. Furthermore, large effect sizes were found between men and women for the three SLE scores, with a power analysis of $99 \%$ in all cases.

Table 2: Mann-Whitney U test results

\begin{tabular}{ccccccccc}
\hline \multicolumn{10}{c}{ Sex } \\
\hline \multicolumn{10}{c}{ Men } & \multicolumn{1}{c}{ Women } \\
\hline SUM SLEs & $\begin{array}{c}\text { Average } \\
\text { range }\end{array}$ & $\begin{array}{c}\text { Range } \\
\text { sum }\end{array}$ & $\begin{array}{c}\text { Average } \\
\text { range }\end{array}$ & $\begin{array}{c}\text { Range } \\
\text { sum }\end{array}$ & $Z_{(293)}$ & $d$ & $1-\beta$ \\
\hline Childhood SLEs & 128.62 & 20065.00 & 167.93 & 23006.00 & $-3.98^{* *}$ & .53 & .99 \\
Life SLEs & 130.33 & 20332.00 & 165.98 & 22739.00 & $-3.61^{* *}$ & .47 & .99 \\
Total SLEs & 125.79 & 19623.50 & 171.15 & 23447.50 & $-4.56^{* *}$ & .60 & .99 \\
\hline$* p<05 ; * * p .001$ & & & & & & &
\end{tabular}




\section{Differences in experiencing stressful life events in childhood and adolescence (before 18 years old) between men and women living homeless}

As can be seen in Table 3, although the percentages of experiencing from SLEs were quite high among both men and women experiencing homelessness, the $\chi^{2}$ test showed several SLEs that occurred in childhood and adolescence for which women scored significantly higher than men. The SLEs for which there are significant differences according to the gender were classified according to the effect size (both Phi and OR): 1) Events such as having experienced significant financial problems in childhood, family members being unemployed for a prolonged period of time, parents having an physically incapacitating health problem, serious fights and arguments with parents or with someone in the family, parental divorce or being thrown out of home have a small effect size, i.e. the possibility of presenting these SLEs in childhood and adolescence among women experiencing homelessness is 1.5 - 2 times higher than among their male counterparts; 2) Meanwhile, events as having parents with serious mental health problems, problems of violence in the family or experiencing abuse in childhood and adolescence have a medium-large effect size, i.e. the possibility of presenting these SLEs in childhood and adolescence among homeless women is 2.5 - 3.5 times greater than among their male counterparts; and 3) the effect size of suffering from sexual violence warrants special mention, as the possibility of suffering from sexual abuse in childhood and adolescence among homeless women is 9.4 times greater than among their male counterparts. 
Table 3: Differences in experiencing stressful life events in childhood and adolescence between men and women living homeless

\begin{tabular}{|c|c|c|c|c|c|c|}
\hline Stressful life events experienced before the age of 18 & $\begin{array}{c}\text { Men } \\
(\mathrm{n}=156)\end{array}$ & $\begin{array}{l}\text { Women } \\
(\mathrm{n}=137)\end{array}$ & $\chi^{2}(1)$ & $\phi$ & OR & CI $95 \%$ \\
\hline Major financial problems & $25.6 \%$ & $36.5 \%$ & $4.04 *$ & $.12 *$ & 1.67 & $1.01-2.75$ \\
\hline Prolonged unemployment of a member of their family & $15.4 \%$ & $24.8 \%$ & $4.09 *$ & $.12 *$ & 1.82 & $1.02-3.25$ \\
\hline A parent had a physically incapacitating health problem & $17.3 \%$ & $28.5 \%$ & $5.21 *$ & $.13^{*}$ & 1.90 & $1.09-3.32$ \\
\hline A parent had a serious mental health problem & $4.5 \%$ & $13.9 \%$ & $7.94^{*}$ & $.17^{*}$ & 3.43 & $1.39-8.43$ \\
\hline A parent had problems with alcohol or drugs & $25 \%$ & $35 \%$ & 3,52 & .11 & 1.61 & $0.97-2.68$ \\
\hline A parent left the family home & $17.3 \%$ & $26.3 \%$ & 3.48 & .11 & 1.70 & $0.97-2.99$ \\
\hline Serious fights and arguments between the parents & $25 \%$ & $38.7 \%$ & $6.34 *$ & $.15^{*}$ & 1.89 & $1.15-3.12$ \\
\hline Problems of family violence & $21.2 \%$ & $40.9 \%$ & $13.42 * *$ & $.21 * *$ & 2.58 & $1.54-4.31$ \\
\hline One of their parents was in prison & $8.3 \%$ & $9.5 \%$ & 0.12 & .02 & 1.15 & $.52-2.581$ \\
\hline Serious conflicts between them and your family & $21.8 \%$ & $32.8 \%$ & $4.52 *$ & $.12 *$ & 1.76 & $1.04-2.96$ \\
\hline Frequent changes of residence & $17.3 \%$ & $19.7 \%$ & 0.28 & .03 & 1.17 & $0.65-2.12$ \\
\hline Suffered abuse & $17.9 \%$ & $42.3 \%$ & $20.92 * *$ & $.27 * *$ & 3.36 & $1.97-5.71$ \\
\hline Suffered sexual abuse & $4.5 \%$ & $30.7 \%$ & $35.87 * *$ & $.35^{* *}$ & 9.41 & $4.06-21.81$ \\
\hline Thrown out of home & $8.3 \%$ & $19.7 \%$ & $8.01 *$ & $.17 *$ & 2.70 & $1.33-5.47$ \\
\hline He or she was abandoned & $7.1 \%$ & $13.9 \%$ & 3.69 & .11 & 2.12 & $0.97-4.64$ \\
\hline Ran away from home & $28.8 \%$ & $34.3 \%$ & 1.01 & .06 & 1.29 & $0.79-2.11$ \\
\hline Parents divorced or separated & $17.3 \%$ & $28.5 \%$ & $5.21 *$ & $.13^{*}$ & 1.90 & $1.09-3.32$ \\
\hline Brought up by people other than their parents & $26.3 \%$ & $32.1 \%$ & 1.21 & .06 & 1.33 & $0.8-2.2$ \\
\hline Housing problems in childhood & $7.1 \%$ & $13.9 \%$ & 3.69 & .11 & 2.12 & $0.97-4.64$ \\
\hline Dropped out of school & $39.1 \%$ & $32.1 \%$ & 1.55 & -.07 & 0.74 & $0.46-1.19$ \\
\hline Expelled from school & $17.3 \%$ & $10.2 \%$ & 3.05 & -.10 & 0.54 & $0.27-1.09$ \\
\hline
\end{tabular}




\section{Differences in experiencing stressful life events at some point in their lives between men and women living homeless}

The results of this analysis are shown in the Table 4 . The $\chi^{2}$ test showed several SLEs that occurred throughout the individuals' lives in which homeless women scored significantly higher than homeless men. However, unlike the results found when studying SLEs in childhood and adolescence, in this case a series of SLEs were also observed for which men scored significantly higher than women.

Women living homeless experience the following events to a greater extent than their male counterparts: the death of their spouse or partner, unemployment problems and important financial problems, mental health problems and psychiatric hospitalizations, sexual assault in adulthood, abuse by a spouse or partner, physical violence in adulthood, and suicide attempts at some point in their life. Of these events, mental health problems, sexual assault, abuse and physical violence in adulthood have particularly large effect sizes. The differences in sexual assault and abuse by the spouse or partner are particularly striking, as the likelihood of experiencing these SLEs during adult life among women who were homeless is more than 10 times higher the rate for their male counterparts.

However, men living homeless experienced the following events to a greater extent than women: drinking excessively at some point in their life, having been reported to the police, and having been arrested or detained. The differences compared to homeless women have a large effect size for these three events. 
Table 4: Differences in experiencing stressful life events at some point in their lives between men and women living homeless

\begin{tabular}{|c|c|c|c|c|c|c|}
\hline Stressful life events after the age of 18 & $\begin{array}{c}\text { Men } \\
(n=156)\end{array}$ & $\begin{array}{l}\text { Women } \\
(\mathrm{n}=137)\end{array}$ & $\chi^{2}(1)$ & $\phi$ & OR & CI $95 \%$ \\
\hline Death of father & $66.7 \%$ & $65 \%$ & 0.09 & -.02 & 0.93 & $0.57-1.50$ \\
\hline Death of mother & $51.3 \%$ & $47.4 \%$ & 0.43 & -.04 & 0.86 & $0.54-1.36$ \\
\hline Death of spouse or partner & $10.3 \%$ & $21.2 \%$ & $6.68^{*}$ & $.15^{*}$ & 2.35 & $1.21-4.55$ \\
\hline Death of a child & $4.5 \%$ & $4.4 \%$ & 0.00 & -.00 & 0.98 & $0.32-2.97$ \\
\hline Suffered from a serious illness, injury or accident & $47.4 \%$ & $52.6 \%$ & 0.77 & .05 & 1.23 & $0.78-1.94$ \\
\hline Separation or divorce from spouse & $57.1 \%$ & $48.2 \%$ & 2.31 & -.09 & 0.70 & $0.44-1.11$ \\
\hline Suffered from serious unemployment problems & $67.3 \%$ & $79.6 \%$ & $5.56^{*}$ & $.14^{*}$ & 1.89 & $1.11-3.22$ \\
\hline Suffered from major financial problems & $66.7 \%$ & $85.4 \%$ & $13.81 * *$ & $.22 * *$ & 2.93 & $1.64-5.22$ \\
\hline Drunk too much at some point in their life & $58.3 \%$ & $35.8 \%$ & $14.89 * *$ & $-.23 * *$ & 0.40 & $0.25-0.64$ \\
\hline Abused drugs at some point in their life & $34 \%$ & $37.2 \%$ & 0.34 & .03 & 1.15 & $0.71-1.86$ \\
\hline Been in prison & $32.7 \%$ & $24.1 \%$ & 2.64 & -.10 & 0.65 & $0.39-1.09$ \\
\hline Admitted to a psychiatric hospital & $19.2 \%$ & $29.9 \%$ & $4.55^{*}$ & $.13 *$ & 1.79 & $1.05-3.08$ \\
\hline Done work that separated them from their home & $41 \%$ & $37.2 \%$ & 0.44 & -.04 & 0.85 & $0.53-1.37$ \\
\hline Lost their home due to eviction & $24.4 \%$ & $19.7 \%$ & 0.91 & -.06 & 0.76 & $0.44-1.33$ \\
\hline Emigrated from their country of origin & $39.7 \%$ & $47.4 \%$ & 1.76 & .08 & 1.37 & $0.86-2.18$ \\
\hline Left their partner and/or children in their place of origin & $15.4 \%$ & $20.4 \%$ & 1.28 & .07 & 1.41 & $0.77-2.58$ \\
\hline Had a serious mental health problem & $18.6 \%$ & $39.4 \%$ & $15.58 * *$ & $.23 * *$ & 2.85 & $1.68-4.84$ \\
\hline Suffered from sexual assault (over 18 years old) & $3.8 \%$ & $35 \%$ & $47.20 * *$ & $.40^{* *}$ & 13.48 & $5.55-32.78$ \\
\hline Suffered from abuse by their spouse or partner & $11.5 \%$ & $57.7 \%$ & $70.08 * *$ & $.49^{* *}$ & 10.44 & $5.75-18.97$ \\
\hline Suffered from physical violence & $21.2 \%$ & $54 \%$ & $33.98 * *$ & $.34 * *$ & 4.38 & $2.63-7.29$ \\
\hline Had attempted suicide & $30.8 \%$ & $48.9 \%$ & $10.06^{*}$ & $.19^{*}$ & 2.15 & $1.34-3.47$ \\
\hline Reported to the police & $50.6 \%$ & $35 \%$ & $7.23 *$ & $-.16^{*}$ & 0.53 & $0.33-.84$ \\
\hline Arrested or detained for a crime & $51.9 \%$ & $38.7 \%$ & $5.15^{*}$ & $-.13 *$ & 0.58 & $0.37-.93$ \\
\hline Convicted of a crime & $34 \%$ & $25.5 \%$ & 2.47 & -.09 & 0.67 & $0.40-1.11$ \\
\hline
\end{tabular}

$* p<.05 ; * * p<.001$ 


\section{Discussion}

The aim of this study was to examine the differences between men and women who were homeless in terms of the number and type of SLEs experienced during their lives (childhood, adolescence and adulthood). The results of this study confirmed our three hypotheses: men and women living homeless experience different number and types of SLEs, both in childhood and adolescence and throughout their lives. These findings are consistent with the results of other studies carried out in U.S.-based samples (Wenzel et al., 2001; Zugazaga, 2004), expanding these results to the idiosyncratic characteristics of the Spanish population by using a large sample size to analyze the events experienced at different times in the life course.

First, the data show differences in the number of SLEs experienced by homeless men and women. As pointed out by Padgett et al. (2012), the results suggest that women experiencing homelessness generally suffer from more SLEs. Unlike the results obtained by Coates and McKenzie-Mohr (2010), the results of this study not only show that women living homeless experience more SLEs, but also that these differences seem to remain constant in childhood and adolescence and throughout their lives. In fact, the data found showed that women living homeless experience approximately an average of four more SLEs than their male counterparts in total, and two more along the childhood and adolescence.

Second, the results also show differences in the types of SLEs experienced by men and women living homeless. In line with the findings of Hatch and Dohrenwend (2007), the data from our study indicate that men living homeless tend to experience more events related to substance abuse and legal problems, while their female counterparts tend to experience more including abuse (physical, sexual and psychological), violence by a spouse/partner and psychiatric hospitalization.

When the SLEs experienced in childhood and adolescence are examined in detail, women living homeless are observed to have experienced a much wider variety of events to a greater extent than men living homeless. As with the results obtained by Hatch and Dohrenwend (2007), homeless women experience childhoods characterized by SLEs within their relationship with their parents to a greater extent than their male counterparts: these events include parents with a physically disable health problem, parents with serious mental health problems, separated or divorced parents, and serious fights and arguments between their parents. These high levels of breakdown in family structures could be the reason behind more women experiencing homelessness having been thrown out of their family home than their male counterparts.

However, events related to problems of violence within the family, abuse and episodes of sexual violence are the events with the most marked differences for homeless men and women during their childhood and adolescence. Several studies conducted on both European and U.S.-based samples have highlighted the high prevalence of physical and/or sexual violence during the childhood of women experiencing homelessness (Coates \& McKenzie-Mohr, 2010; Hatch \& Dohrenwend, 2007; Noell et al., 2001; Sundin \& Baguley, 2015; Vázquez \& Panadero, 2019; Zugazaga, 2004). The results of this study show that the probability of experiencing this type of event is about three times higher among women living homeless than among men living homeless. Suffering from sexual violence in childhood and adolescence is particularly noteworthy, as homeless women are 9.4 times more likely to have experienced sexual violence in childhood and adolescence than their male counterparts, and this finding consistent with the results of 
previous studies (Taylor et al., 2008). This tendency consistently appears in the general population, where women are observed to suffer from abuse in childhood to a greater extent than men (MacMillan et al., 2014).

Third, this study does not find differences between men and women experiencing homelessness as regards other events such as foster care, which affects a significant percentage of people living homeless and which has been highlighted by some authors as a risk factor for homelessness (Bassuk et al, 1997). As mentioned above, homeless men do not score higher than women for any SLE occurring in childhood and adolescence.

Fourth, when the different types of SLEs experienced by homeless men and women during their lives are examined, the results were very similar to those reported in previous studies (Hatch \& Dohrenwend, 2007; Zugazaga, 2004). Our result show that homeless women experience different SLEs throughout their lives, which could be classified into two main groups: a) material SLEs: women living homeless have more important economic problems and serious unemployment problems to a greater extent than men and b) interpersonal SLEs: women living homeless experience high rates of abuse by a spouse or partner, sexual assault and problems of physical violence after age 18 , and these rates are higher than for men in the same situation in all cases. The issue of gender violence among women living homeless has been the focus of particular interest, and has been highlighted on many occasions as a risk factor for homelessness itself (Bassuk et al., 1997; Bassuk et al., 2006; Johnson et al., 2017; Lehmann et al., 2007). More than half of the women participating in this study had experienced abuse by their spouse or partner.

Many studies have focused on various aspects of the relationship between homelessness and health (the state of physical and mental health of individuals experiencing homelessness, their subjective perception of health, mortality, access to health resources, habits related to health, etc.) and have shown that people living homeless have significant difficulties in this area (Aldridge et al., 2018; Frankish et al., 2005). Although the health of women experiencing homelessness has been studied to a lesser extent, some of the data available seem to suggest that homelessness is strongly linked to these women's poor health and inadequate use of resources (Arangua et al., 2005). In this study, the data suggest a significant degree of health problems among the participants in both groups. In general, no differences were found between men and women in terms of experiencing illness, injury or serious accidents, which affected approximately half of the male and female participants.

However, these results suggest that there are clear differences between men and women experiencing homelessness in the mental health outcomes. Specifically, women reported higher rates of serious mental health problems and psychiatric hospitalizations than men. Some studies conducted in U.S. have identified a strong relationship between serious mental health problems and homelessness in women (Roll et al., 1999; Tsai et al., 2014), which could be even further accentuated among women who literally spend the night on the street (Nyamathi et al., 2000). Meanwhile, a closer relationship between disorders related to substance use and homelessness has been identified among men (Tsai et al., 2014; Zugazaga, 2004). Indeed, this study shows a greater frequency of problems related to alcohol consumption among men experiencing homelessness, although this is not the case with consumption of other substances, unlike other studies, in which men living homeless present more problems related to drug use than their female counterparts (Hatch \& Dohrenwend, 2007; Tsai et al., 2014; Zugazaga, 2004). These differences could 
indicate differences between men and women in risk factors for homelessness, and different needs in both preventing and dealing with homelessness.

Meanwhile, as well as more problems related to alcohol consumption, men who were homeless experience more complaints to the police and arrests than women. These findings are consistent with the data reported by Hatch and Dohrenwend (2007) and Zugazaga (2004). The study by Zugazaga (2004) also found that homeless men experienced imprisonment, conviction, accidents, physical injuries and loss of employment to a greater extent than homeless women, although these differences are not reflected in this study.

Some authors have pointed out that the risk of suicide seems to increase very significantly among people living homeless, and that it could be six times higher than among the general population (Hwang et al., 2009). The data from this study are very worrying as regards suicidal behavior among people experiencing homelessness, and about suicide attempts in particular. Nearly one in three men and one in two women participating in the study had attempted suicide at some point in their lives. Some studies indicate that the largest proportion of suicide attempts among women living homeless could be related to experiencing various SLEs, such as childhood abuse or mental disorders (Dietz, 2010; McHolm et al., 2014; Vázquez \& Panadero, 2019). These gender differences are also observed in the general population, as although women attempt suicide to a greater extent than men, men have higher rates of completed suicides (Bertolote \& Fleischmann, 2015). This is consistent with the results of the study by Barak et al. (2004), who found a higher number of completed suicides among men living homeless, although other authors have suggested that mortality rates due to suicide among women experiencing homelessness could be higher than those among men in the same situation (Hwang et al., 2009).

However, the results must be considered with some degree of caution bearing in mind the limitations of the study. Despite the extensive range of the events studied, some areas may require more in-depth analysis (e.g. mental illness, consumption problems and suicide), which could help to clarify some of the results. Future studies should combine quantitative and qualitative research in order to provide greater insights into the lives of men and women experiencing homelessness (e.g. Cronley et al., 2020). Moreover, the study was conducted in a single community-based sample in Madrid (Spain), so we must be careful to generalize these results. The available information seems to suggest that there are important differences in gender-based services (Montgomery \& Byrne, 2014), so future studies should explore cross-sectional samples to analyze those differences. Furthermore, results are not compared to a control group and only cross-sectional data were included in the study. Futures studies should include longitudinal data to better understand the relationship between SLEs and homelessness. Knowing whether events occurred before or after the homeless situation would improve our knowledge on the relationship between these variables. Given the narrow in scope of bivariate inferential analyses, future studies should also seek to how differences in SLEs predict different outcomes for men and women within the context of homelessness. Furthermore, the multiple simultaneous statistical tests carried out in our study could produce a multiple comparison problem, so future studies should take on a more confirmatory approach based on our exploratory results, reducing the huge number of events relevant for this population. Unfortunately, transgender experiences were not evaluated in his study. Future research should adopt a non-binary gender identity framework, analyzing the 
transgender individual's experiences compared to cis-gender male and female (e.g., Begun \& Kattari, 2016).

In-depth knowledge of the gender differences among individuals experiencing homelessness as regards suffering from these events could be a key factor in the design of social services and policies that are sensitive to the specific needs of this group. In these cases, the policymakers should support the development of specific interventions to protect this particularly vulnerable subgroup. These interventions could be divided into two main groups. First, there should be interventions of a preventive nature, which are based on considering SLEs as a factor in vulnerability to homelessness. Thoits (2010) emphasizes the importance of taking into account the long-term effects of experiences that occurred in childhood, and examining their lasting consequences in adult life. Preventive interventions at this level should involve early detection of the possible occurrence of the SLEs mentioned in the results of this study, and should pay particular attention to high-risk groups such as women (Kim \& Ford, 2006; Lee et al., 2010). The second group are interventions specifically aimed at the inclusion of people living homeless: from this perspective, the services designed must consider homelessness as a vulnerability factor that increases the risk of suffering from more SLEs while the individual concerned is living homeless (Tsai et al., 2014), and they should take gender differences into account when designing these interventions. For instance, Housing First models have shown to be a cost-effective alternative to the traditional emergency shelters and housing progression (Tsemberis, 2010). However, such programs have shown to be more effective when are designed considering the specific needs and characteristics of women experiencing homelessness (Oudshoorn et al., 2018). For all these interventions to be effective they require case workers, program administrators, and policy makers who possess an immediate awareness of the lived stressful experiences of individuals experiencing homelessness.

\section{References}

Aldridge, R. W., Story, A., Hwang, S. W., Nordentoft, M., Luchenski, S. A., Hartwell, G., \& Hayward, A. C. (2018). Morbidity and mortality in homeless individuals, prisoners, sex workers, and individuals with substance use disorders in high-income countries: a systematic review and meta-analysis. The Lancet, 391(10117), 241250. https://doi.org/10.1016/S0140-6736(17)31869-X

Arangua, L., Andersen, R., \& Gelberg, L. (2005). The health circumstances of homeless women in the United States. International Journal of Mental Health, 34(2), 62-92. https://doi.org/10.1080/00207411.2005.11043398

Arias, R., Chacon, J., and Castellanos, M. (2015). Analisis de datos en Psicologia y Ciencias de la Salud. Madrid: EOS Instituto de Orientacion Psicologica.

Barak, Y., Cohen, A., \& Aizenberg, D. (2004). Suicide among the homeless: a 9-year case-series analysis. Crisis, 25(2), 51-53. https://doi.org/0.1027/0227-5910.25.2.51

Barrow, S. M. (2004) Homeless women. En D. Levinston (Ed), Encyclopedia of Homelessness. London: SAGE

Bassuk, E. L., Buckner, J. C., Weinreb, L. F., Browne, A., Bassuk, S. S., Dawson, R., \& Perloff, J. N. (1997). Homelessness in female-headed families: childhood and adult risk and protective factors. American Journal of Public Health, 87(2), 241-248. https://doi.org/10.2105/AJPH.87.2.241 
Bassuk, E.L., Dawson, R., \& Huntington, N. (2006). Intimate partner violence in extremely poor women: longitudinal patterns and risk markers. Journal of Family Violence, 21(6), 387-399. https://doi.org/10.1007/s10896-006-9035-1

Begun, S., \& Kattari, S. K. (2016). Conforming for survival: Associations between transgender visual conformity/passing and homelessness experiences. Journal of Gay \& Lesbian Social Services, 28(1), 54-66. https://doi.org/10.1080/10538720.2016.1125821

Bertolote J. M., \& Fleischmann, A. (2015) A global perspective in the epidemiology of suicide. Suicidologi, 7. Link: https://goo.gl/GKLpxy

Bowpitt, G., Dwyer, P., Sundin, E., \& Weinstein, M. (2011). Comparing men's and women's experiences of multiple exclusion homelessness. Social Policy and Society, 10(4), 537-546. https://doi.org/10.1017/S1474746411000285

Bretherton, J. (2017). Homelessness and gender reconsidered. European Journal of Homelessness, 11, 1-22.

Brown, R. T., Goodman, L., Guzman, D., Tieu, L., Ponath, C., \& Kushel, M. B. (2016). Pathways to homelessness among older homeless adults: Results from the HOPE HOME Study. PLoS One, 11(5). https://doi.org/10.1371/journal.pone.0155065

Byrne, T., Montgomery, A. E., \& Fargo, J. D. (2016). Unsheltered homelessness among veterans: correlates and profiles. Community Mental Health Journal, 52(2), 148157.

Coates, J., \& McKenzie-Mohr, S. (2010). Out of the frying pan, into the fire: Trauma in the lives of homeless youth prior to and during homelessness. Journal of Sociology \& Social Welfare, 37, 65-98.

Cronley, C., Murphy, E. R., \& Petrovich, J. C. (2020). Homelessness from a holistic paradigm: Bridging gaps in curriculum through supplemental education opportunities. Journal of Social Work Education, 1-12. https://doi.org/10.1080/10437797.2020.1723762

Dietz, T. L. (2010). Substance misuse, suicidal ideation, and suicide attempts among a national sample of homeless. Journal of Social Service Research, 37(1), 1-18. https://doi.org/10.1080/01488376.2011.524511

European Commission (2009). Joint report on social protection and social inclusion. Luxembourg: Office for Official Publications of the European Communities.

Fazel, S., Geddes, J. R., \& Kushel, M. (2014). The health of homeless people in highincome countries: Descriptive epidemiology, health consequences, and clinical and policy recommendations. The Lancet, 384 (9953), 1529-1540. doi:10.1016/S01406736(14)61132-6.

Frankish, C. J., Hwang, S. W., \& Quantz, D. (2005). Homelessness and health in Canada: Research lessons and priorities. Canadian Journal of Public Health, 96(2), S23S29.

Guillén, A. I., Panadero, S., Rivas, E., \& Vázquez, J. J. (2015). Suicide attempts and stressful life events among female victims of intimate partner violence living in poverty in Nicaragua. Scandinavian Journal of Psychology, 56(3), 349-356. https://doi.org/10.1111/sjop.12207 
Hair, J. F., Black, W. C., Babin, B. J., \& Anderson, R. E. (2014). Multivariate data analysis: Pearson new international edition (7th ed.). Harlow, UK: Pearson Education.

Hatch, S. L., \& Dohrenwend, B. P. (2007). Distribution of traumatic and other stressful life events by race/ethnicity, gender, SES and age: A review of the research. American Journal of Community Psychology, 40(3-4), 313-332. https://doi.org/10.1007/s10464-007-9134-z

Herman, D. B., Susser, E. S., Struening, E. L., \& Link, B. L. (1997). Adverse childhood experiences: are they risk factors for adult homelessness? American Journal of Public Health, 87(2) 249-255. https://doi.org/10.2105/AJPH.87.2.249

Hwang, S. W., Wilkins, R., Tjepkema, M., O’Campo, P. J., \& Dunn, J. R. (2009). Mortality among residents of shelters, rooming houses, and hotels in Canada: 11 year follow-up study. British Medical Journal, 339. https://doi.org/10.1136/bmj.b4036

Jasinski, J. L., Wesely, J. K., Mustaine, E., \& Wright, J. D. (2005). The experience of violence in the lives of homeless women: A Research Report. Report for the National Institute of Justice (USA).

Johnson, G., Ribar, D. C., \& Zhu, A. (2017). Women's homelessness: international evidence on causes, consequences, coping and policies. Melbourne. Institute Working Paper No. 7/17. Retrieved from https://ssrn.com/abstract=2927811

Kim, M. M., \& Ford, J. D. (2006). Trauma and post-traumatic stress among homeless men: A review of current research. Journal of Aggression, Maltreatment, and Trauma, 13(2), 1-22. https://doi.org/10.1300/J146v13n02_01

Koegel, P., Melamid, E., \& Burnam, M. A. (1995). Childhood risk factors for homelessness among homeless adults. American Journal of Public Health, 85(12), 1642-1649. https://doi.org/10.2105/AJPH.85.12.1642

Lee, B. A., Tyler, K. A., \& Wright, J. D. (2010). The new homelessness revisited. Annual Review of Sociology, 36, 500-521. https://doi.org/10.1146/annurev-soc-070308115940

Lehmann, E.R., Drake, C.M., Kass, P.H., \& Nichols, S.B. (2007). Risk factors for firsttime homelessness in low-income women. American Journal Orthopsychiatry, 77(1), 20-28. https://doi.org/10.1037/0002-9432.77.1.20

MacMillan, H., Fleming, J., Streiner, D., Lin, E., Boyle, M., Jamieson, E., ... Beardslee, W. (2014). Childhood abuse and lifetime psychopathology in a community sample. American Journal of Psychiatry, 158(11), 1878-1883. https://doi.org/10.1176/appi.ajp.158.11.1878

Mayock, P., \& Bretherton, J. (2016). Women's homelessness in Europe. London, United Kingdom: Palgrave Macmillan.

McHolm, A. E., MacMillan, H. L., \& Jamieson, E. (2014). The relationship between childhood physical abuse and suicidality among depressed women: results from a community sample. American Journal of Psychiatry, 160(5), 933-938. https://doi.org/10.1176/appi.ajp.160.5.933 
Montgomery, A. E., \& Byrne, T. H. (2014). Services utilization among recently homeless veterans: A gender-based comparison. Military Medicine, 179 (3), 236. https://doi.org/10.7205/MILMED-D-13-00426

Montgomery, A. E., Szymkowiak, D., \& Culhane, D. (2017). Gender differences in factors associated with unsheltered status and increased risk of premature mortality among individuals experiencing homelessness. Women's Health Issues, 27(3), 256263. https://doi.org/10.1016/j.whi.2017.03.014

Muñoz, M., Panadero, S., Pérez, E. \& Quiroga, M.A. (2005). Role of stressful life events in homelessness: An Intragroup analysis. American Journal of Community Psychology, 35, 35-47. https://doi.org/10.1007/s10464-005-1888-6

Muñoz, M., Vázquez, C., Bermejo, M., \& Vázquez, J. J. (1999). Stressful life events among homeless people: quantity, types, timing and perceived causality. Journal of Community Psychology, 27, 73-87. https://doi.org/10.1002/(SICI)15206629(199901)27:1<73::AID-JCOP5>3.0.CO;2-\%23

Noell, J., Rohde, P., Seeley, J., \& Ochs, L. (2001). Childhood sexual abuse, adolescent sexual coercion and sexually transmitted infection acquisition among homeless female adolescents. Child Abuse and Neglect, 25, 137-148. https://doi.org/10.1016/S0145-2134(00)00223-4

Nyamathi, A. M., Leake, B., \& Gelberg, L. (2000). Sheltered versus nonsheltered homeless women. Journal of General Internal Medicine, 15(8), 565-572.

Oudshoorn, A., Forchuk, C., Hall, J., Smith-Carrier, T., \& Van Berkum, A. (2018). An evaluation of a Housing First program for chronically homeless women. Journal of Social Inclusion, 9(2), 34. https://doi.org/10.36251/josi.136

Padgett, D. K., Smith B. T., Henwood, B. F. \& Tiderington, E. (2012). Life course adversity in the lives of formerly homeless persons with serious mental illness: context and meaning. American Journal of Orthopsychiatry, 82(3), 421-30. https://doi.org/10.1111/j.1939-0025.2012.01159.x

Panadero, S., Martín, R., \& Vázquez, J. J. (2018). Suicide attempts and stressful life events among homeless people in Madrid (Spain). Journal of Community \& Applied Social Psychology, 28(4), 200-212. https://doi.org/10.1002/casp.2351

Panadero, S., \& Vázquez, J. J. (2016). En las fronteras de la ciudadanía. Situación de las personas sin hogar y en riesgo de exclusión social en Madrid [On the borders of citizenship. Situation of the homeless and at risk of social exclusion in Madrid]. Alcalá de Henares: Universidad de Alcalá.

Roll, C. N., Toro, P. A., \& Ortola, G. L. (1999). Characteristics and experiences of homeless adults: A comparison of single men, single women, and women with children. Journal of Community Psychology, 27(2), 189-198. https://doi.org/10.1002/(SICI)1520-6629(199903)27:2<189::AID-

JCOP6>3.0.CO;2-M

Sundin, E. C., \& Baguley, T. (2015). Prevalence of childhood abuse among people who are homeless in Western countries: a systematic review and meta-analysis. Social Psychiatry and Psychiatric Epidemiology, 50, 183-194. https://doi.org/10.1007/s00127-014-0937-6 
Taylor, C. A., Boris, N. W., Heller, S. S., Clum, G. A., Rice, J. C., \& Zeanah, C. H. (2008). Cumulative experiences of violence among high-risk urban youth. Journal of Interpersonal Violence, 23(11), 1618-1635. https://doi.org/10.1177/0886260508314323

Thoits, P. A. (2010). Stress and health: Major findings and policy implications. Journal of Health and Social Behavior, 51, 41-53. https://doi.org/10.1177/0022146510383499

Tsai, J., Kasprow, W. J., Kane, V., \& Rosenheck, R. A. (2014). National comparison of literally homeless male and female VA service users: entry characteristics, clinical needs, and service patterns. Women's Health Issues, 24(1), e29-e35. https://doi.org/10.1016/j.whi.2013.09.007

Tsemberis, S. J. (2010). Housing First: The pathways model to end homelessness for people with mental illness and addiction manual. European Journal of Homelessness, 5(2).

Vázquez, J. J., \& Panadero, S. (2019). Suicidal attempts and stressful life events among women in a homeless situation in Madrid (Spain). American Journal of Orthopsychiatry, 89(2), 304-311. https://doi.org/10.1037/ort0000387

Vázquez, J. J., Panadero, S., \& Zúñiga, C. (2018). Attributions about homelessness in homeless and domiciled people in Madrid, Spain: "Why are they homeless people?". American Journal of Orthopsychiatry, 88(2), 236-247. https://doi.org/10.1037/ort0000246

Vázquez, J. J., Suarez, A., Berrios, A., \& Panadero, S. (2019). Stressful life events among homeless people in León (Nicaragua): Quantity, types, timing, and perceived causality. Journal of Community Psychology, 47(1), 176-185. https://doi.org/10.1002/jcop.22102

Wenzel, S.L., Leake, B., \& Gelberg, L. (2001). Risk Factors for Major Violence Among Homeless Women. Journal of Interpersonal Violence, 16(8), 739-752. https://doi.org/10.1177/088626001016008001

Wong, Y. I., \& Piliavin, I. (2001). Stressors, resources and distress among homeless persons: A longitudinal analysis. Social Science and Medicine, 52, 1029-1042. https://doi.org/10.1016/S0277-9536(00)00209-4

Zugazaga, C. (2004). Stressful life event experiences of homeless adults: A comparison of single men, single women, and women with children. Journal of Community Psychology, 32(6), 643-654. https://doi.org/10.1002/jcop.20025 